\title{
RIESGOS, VULNERABILIDAD Y PARADOJAS DEL TURISMO
}

RISKS, VULNERABILITY AND PARADOXES OF TOURISM

\author{
Rafael Cruces Portales \\ CULTURDES/Universidad Miguel Hernández de Elche. \\ rcruces.cm@gmail.com \\ https://orcid.org/0000-0001-5427-4478
}

Recibido/Received: 11/05/2021

Modificado/Modified: 24/09/2021

Aceptado/Accepted: 13/12/2021

\section{RESUMEN}

Este artículo tiene como propósito presentar un análisis del escenario sobrevenido para el turismo tras la inexorable irrupción del coronavirus SARS-CoV-2 en todo el mundo. El examen se realiza desde una epistemología crítica, para abordar las paradojas inmanentes al turismo como constructo social, y propositiva ante la ubicua invocación de una transformación considerada urgente e ineludible. Sin embargo, cabe preguntarse si se dan los prerrequisitos necesarios para que esa transformación se materialice.

El riesgo latente de una pandemia mundial se había llegado a insinuar en varias ocasiones hasta que finalmente cristalizó a partir del primer trimestre de 2020 extendiéndose de forma progresiva y dando como resultado un insólito escenario de dimensiones planetarias cuasi apocalípticas. El turismo ha mostrado, una vez más, su vulnerabilidad como sistema sujeto a múltiples contingencias internas y externas. La pandemia del COVID-19 ha sido el súbito detonante de una implosión que desvela al fenómeno turístico como un ídolo con pies de barro. Nos ha mostrado con fidelidad hiperrealista que "lo turístico", aun sustentado por una poderosa industria multisectorial, globalizada y mundializada adolece de reactivos y engranajes para enfrentar embates semejantes.

Esto nos lleva a concluir la necesidad de repensar el modelo de turismo actual eliminando sus contradicciones, y formular un nuevo paradigma post-pandemia que lo dote de mayor coherencia. Asimismo, es preciso reelaborar y reorientar las distintas narrativas de manera que confluyan en un discurso que se distinga por su impronta performativa. Para que se produzca esa catarsis la industria tendrá que preguntarse si está dispuesta a seguir con rigor las pautas de la sostenibilidad para evitar, o al menos reducir las consecuencias de crisis venideras. También la sociedad, y cada uno de nosotros, como potenciales turistas tendremos que preguntarnos qué hemos aprendido y cómo contribuiremos a la regeneración del turismo.

PALABRAS CLAVE

COVID-19, riesgo, vulnerabilidad, paradoja, sostenibilidad, regeneración, turismo

\section{SUMARIO}

1. Introducción. 2. Riesgos y paradojas del Turismo: relaciones de dependencia. 3. Turismo y Vulnerabilidad. 4. El turismo postpandemia: retos y oportunidad de transformación. 5. Conclusiones. 6. Bibliografia.

\section{ABSTRACT}


The purpose of this article is to present an analysis of the scenario for tourism after the inexorable outbreak of the SARS-CoV-2 coronavirus around the world. The examination is carried out from a critical epistemology, to address the paradoxes inherent to tourism as a social construct and propositional before the ubiquitous invocation of a transformation considered urgent and inescapable. However, the question is whether the necessary prerequisites are in place for this transformation to materialize.

The latent risk of a global pandemic had been hinted at on several occasions until it finally crystallized from the first quarter of 2020, spreading progressively and resulting in an unusual scenario of quasiapocalyptic planetary dimensions. Tourism has shown, once again, its vulnerability as a system subject to multiple internal and external contingencies. The COVID-19 pandemic has been the sudden trigger for an implosion that reveals the tourist phenomenon as an idol with feet of clay. It has shown us with hyperrealistic fidelity that "tourism", even supported by a powerful multisectoral and globalized industry, lacks reagents and gears to face similar attacks.

This leads us to conclude the need to rethink the current tourism model, eliminating its contradictions, and formulate a new post-pandemic paradigm that provides it with greater coherence. Likewise, it is necessary to rework and reorient the different narratives so that they converge in a discourse that is distinguished by its performative stamp. For this catharsis to occur, the industry will have to ask itself whether it is willing to rigorously follow sustainability guidelines to avoid, or at least reduce the consequences of future crises. Also society, and each one of us, as potential tourists, will have to ask ourselves what we have learned and how we will contribute to the regeneration of tourism.

\section{KEYWORDS}

COVID-19, risk, vulnerability, paradox, sustainability, regeneration, tourism

\section{CONTENTS}

1. Introduction. 2. Risks and paradoxes of Tourism: dependency relationships. 3. Tourism and Vulnerability. 4. Post-pandemic tourism: challenges and opportunities for transformation. 5. Conclusions. 6. References.

\section{INTRODUCCIÓN}

El turismo es un fenómeno económico, social y cultural que a pesar de ser, como afirma Nogués Pedregal (Yanes y Travé, 2020), la creación más perfecta y sofisticada del sistema de valores capitalista, presenta una serie de paradojas que son consecuencia directa de desajustes entre sus elementos constitutivos. De estos desequilibrios homeostáticos del sistema emergen una serie de riesgos que disparan su vulnerabilidad evidenciando la fragilidad de una estructura, aparentemente, muy sólida pero, que oculta contradicciones que la debilitan ante las amenazas externas (Rodriguez-Toubes y Álvarez de la Torre, 2013).

El riesgo latente más amenazante al que se expone el turismo es, como ha quedado patente, la paralización de la movilidad internacional. Esta falta, o reducción significativa, de movimiento de turistas a nivel mundial deprime la producción y actividad turística hasta retrotraerlas a niveles de varias décadas atrás. La pandemia del COVID-19, de forma súbita, ha frenado en seco la movilidad consustancial al ser humano dibujando un escenario inédito para el turismo forzándolo a un estado de hibernación que se está prolongando y causando perjuicios significativos. Merced a la aparición, y puesta a disposición, de varias vacunas contra el virus SARS-CoV-2 se comienza a atisbar el momento de una reanudación de la actividad que, sin embargo, se presume lenta, gradual e incierta (Fernández, 2021). 
El término "turismo" contiene un valor polisémico muy amplio y diverso que, sin embargo, suele ser percibido desde el reduccionismo. Para intentar superar este lastre hemos realizado un recorrido crítico por lo que hemos denominado "lo turístico", por sus paradojas inmanentes, los factores de riesgo a los que se expone y la vulnerabilidad sistémica que deriva de la interacción contingente de sus variables. Cuando hablamos de "lo turístico" queremos representar un multiverso denso compuesto por multiagentes, prácticas, procesos y recursos interactuando de manera interdependiente en una dimensión espacio-temporal cuyo resultado es una multiplicidad de relaciones sociales, culturales y económicas complejas con capacidad de modificar la vida de los agentes y el entorno. (De la Torre y Navarrete, 2013).

Este multiverso de "lo turístico" viene siendo intensamente cuestionado desde que hace un par de décadas, optara por potenciar estrategias y técnicas de maximización que lo están conduciendo a la extenuación. No obstante, la pandemia mundial lo ha sacudido vigorosamente enfrentándolo a un escenario insólito que aconseja una reflexión profunda sobre la mejor manera de afrontar la reanudación de la actividad (Valle, 2020). Para que este reto se convierta en una oportunidad de transformación regenerativa hemos planteado la conveniencia de priorizar, sin demora, una reactivación proyectada desde un enfoque sostenible. Adoptar un nuevo modelo que propicie el máximo respeto al medioambiente, la biodiversidad y los ecosistemas (Fuchs \& Reichel, 2010). Así como de los entornos y destinos donde la experiencia turística se ha de producir. Un modelo que incluya la participación activa de las comunidades locales en la economía del destino favoreciendo la preservación de su identidad cultural única. Un modelo que apueste por la implantación de un turismo circular, basado en los principios de la economía circular regenerativa de las 5Rs (Posada, 2020). Un modelo que se alíe con la transformación digital, y que fomente la continua incorporación de nuevos destinos turísticos inteligentes a la Red DTI favoreciendo la Innovación, Tecnología, Accesibilidad, Sostenibilidad y Gobernanza como pilares del proyecto transformador y regenerativo de "lo turístico".

\section{RIESGOS Y PARADOJAS DEL TURISMO: RELACIONES DE DEPENDENCIA}

Riesgo y turismo son dos términos que aluden a circunstancias complejas de origen social que están estrechamente conectadas por su interdependencia. El binomio formado por riesgo y turismo ha sido tenido en cuenta de manera laxa por la industria, y también las administraciones públicas, hasta el día de hoy. Esto lo podemos comprobar a través del escaso interés y esfuerzo dedicados a la prevención, la reducción y el control de acciones y eventos que pudieran devenir peligrosas o perjudiciales para el propio turismo, así como para la sociedad en su conjunto (Korstanje, 2013). Esta actitud, aunque ha reflejado en numerosas ocasiones una alta vulnerabilidad del turismo, ha sido, hábilmente, solapada por su sólida capacidad de respuesta, por su resiliencia.

La conciencia de riesgo se ha configurado para soportar una carga de incertidumbre que excede los márgenes de la racionalidad (Beck, 2004). En el ámbito del turismo esto se traduce en la paradoja de no cimentar su rentabilidad productiva sobre la asunción prioritaria de la seguridad de su entorno. Esta pandemia global ha venido a dejar las cosas claras, sobre todo a industria e instituciones públicas, lanzando un mensaje inapelable sobre la clasificación de las prioridades del turismo. A partir de ahora, parece irrefutable que la previsión del riesgo es anterior, y ocupa un lugar prominente, al objetivo del beneficio económico, en una escala de prevalencia. El escenario inimaginable de “turista cero", inédito 
en la era moderna, y consecuencia del insólito período de confinamiento radical que hemos vivido, no deja lugar a dudas sobre las graves repercusiones, de todo orden, que subestimar los riesgos a los que el turismo está expuesto, puede acarrear.

Existen riesgos de diferente índole que pueden influir, afectar o incluso determinar la actividad turística, como aún estamos comprobando. Entre esos riesgos nos referiremos concretamente a tres de especial relevancia y que tienen la capacidad de desafiar de manera significativa las dinámicas y la sostenibilidad de "lo turístico".

En primer lugar, nos referimos al riesgo medioambiental por prefigurar éste la misma condición de posibilidad del turismo, ya que toda actividad o experiencia turística tiene lugar en un entorno territorial o geográfico determinado, en un destino turístico. Este escenario turístico, en su dimensión espacial, es susceptible de afectación por la acción de la naturaleza, que puede presentar alteraciones climáticas, excesos de calor y/o frío, riadas, huracanes, tornados, tsunamis, etc. Los efectos de estas alteraciones inciden de manera notable en la actividad turística, en ocasiones amenazando la integridad física de los turistas y de las infraestructuras de los "santuarios turísticos" (Jafari, 1988). La probabilidad de llegar a paralizarla, aconseja una actuación proactiva ante dichos riesgos, en lugar de aplicar soluciones reactivas, siempre más costosas y traumáticas. Otra manifestación del riesgo medioambiental puede derivarse de la acción humana directa, como los accidentes de tipo nuclear o los vertidos masivos de petróleo en el mar, por citar solo algunos de los más devastadores.

El riesgo medioambiental suele relacionarse con la disrupción de un cambio climático gradual en su aparición pero, drástico en sus efectos. Sin embargo, también puede expresarse en forma de amenaza vírica, como ya lo ha hecho en cuatro ocasiones desde que comenzara el nuevo milenio. En 2002 apareció, como primer aviso, el SARS-CoV-1 originado en China (Cantón) y propagado a una treintena de países durante 2003 ocasionando medidas restrictivas de orden precautorio a la hora de acceder a los medios de transporte aéreo y marítimo en el turismo internacional.

Pero, ha sido durante la segunda década cuando hemos experimentado un incremento preocupante de este tipo de episodios, ya que al comienzo, en 2012, se produjo la irrupción del virus MERS-CoV en Oriente Medio, con su origen en Arabia Saudí. Aunque pudo controlarse con relativa prontitud y sin que los efectos sobre el turismo fueran importantes y globales, hubo algunas zonas, como el caso de Corea del Sur, donde se notó una disminución del número de visitantes del $37 \%$ y reducción de ingresos por turismo de 2.600 millones de dólares que supuso una minoración del 0,2\% en el PIB del año 2015 (Joo, et al, 2019). Dos años más tarde, entre 2014 y 2016 sucedió un alarmante brote de ÉBOLA que, estuvo localizado en África Occidental donde debido a las carencias de los servicios sanitarios hubo un alto índice de letalidad. Se observaron varios casos en EE.UU. España y Reino Unido con resultado de muerte en alguno de ellos. Asimismo, se realizaron repatriaciones desde países africanos a distintos hospitales centro-europeos con rigurosos procesos de aislamiento. Su repercusión para el turismo no tuvo consecuencias globales pero, sí en toda África. Y como colofón, a finales de 2019 irrumpe, nuevamente desde China (Wuhan), el coronavirus SARS-CoV-2 que ha desencadenado una pandemia de dimensiones colosales en términos de contagiados y fallecidos (Korstanje, 2020). Desde comienzos de 2020, hasta el momento en que escribimos este artículo, ha sumergido a la economía mundial en una crisis sin precedentes, afectando de manera especialmente intensa y duradera al turismo.

Según un importante sector de científicos formado, entre otros, por biólogos, ambientalistas y ecologistas, este es el resultado de la acción humana con capacidad de 
perturbar el equilibrio de la biodiversidad y de los ecosistemas (Jordano, 2017). Como ha quedado patente, estas perturbaciones pueden originarse en un punto determinado del planeta y utilizar como vector de transmisión la fluida movilidad internacional (Menchero, 2020), derivada de un mundo globalizado para expandir de forma incontrolada un virus, en sólo 36 horas, a cualquier lugar de la Tierra, por distante que se encuentre del foco emisor, comportándose como atractor con capacidad de desplegar un incontrolable "efecto mariposa" (Lorenz, 2000). Por estos motivos podemos anunciar como paradoja inherente al turismo, una de origen medioambiental, ya que la actividad turística necesita para su desarrollo una participación óptima y saludable de los aspectos sanitarios y ambientales manteniendo los entornos en estado de seguridad y equilibrio. Pero, a pesar de ser una condición fundamental, parece no encontrar la atención y dedicación propias de aquello que tiene el rango de primordial.

Una industria como la turística, vista desde un prisma pre-pandemia, cuyo desenvolvimiento cuantitativo óptimo requiere de unas vías aéreas a pleno rendimiento, ha encontrado en su palanca principal de desarrollo, la movilidad a gran escala, su mayor desafío y su mayor amenaza. Esta circunstancia supone otra paradoja consustancial al turismo desvelando que un mismo elemento, la movilidad, es su gran fortaleza y, al mismo tiempo, es susceptible de convertirse en su mayor debilidad. Esta contradicción es producto de la interacción de fuerzas internas (necesidad de transportar turistas), y externas (riesgo de transportar patógenos). Este reto interactivo ha cristalizado en la paralización, casi total, del movimiento de turistas por todo el mundo trayendo, además de unos efectos catastróficos, el revelado de la existencia de un riesgo que por estar soterrado, agazapado, no reduce un ápice su potencialidad destructora, sino que, muy al contrario, la incrementa exponencialmente. Los multirriesgos medioambientales latentes sitúan al turismo en la tesitura de caminar hacia alternativas sostenibles en la praxis de su actividad regular, así como plantear soluciones preventivas planificadas mediante protocolos disponibles para la acción ante la probable aparición de eventos similares (Britto y Alencar, 2013).

En segundo lugar, nos referimos a los riesgos de carácter socio-cultural que se hallan imbricados con el fenómeno del turismo como presunto "hecho social total" (Mauss, 1979) en continuo proceso de re-configuración y realización. Desde esta perspectiva aludimos a la bidireccionalidad subyacente a turismo y riesgo que emerge y se materializa a través de la figura imprescindible del turista como agente social y cultural cuya presencia es condición sine qua non para la propia subsistencia del turismo, porque "sin turistas, no hay turismo".

Sin embargo, esa presencia primordial es susceptible de provocar concentraciones espacio-temporales exorbitadas que entrañan graves riesgos para la conservación del patrimonio histórico, cultural y natural de los destinos al tensionar sobremanera las dinámicas, las prácticas y los procesos de "lo turístico". El denominado overtourism o carga excesiva de turistas en determinados períodos, inclusive durante todo el año, en un número creciente de destinos constituye una hipermasificación que excede, en mucho, al "turismo de masas" que alcanzara su apogeo en la década de los años 70 del siglo pasado (De la Calle, 2019).

Estos excesos derivados de una notable falta de previsión y planificación de los flujos por parte de la industria y las instituciones públicas del ramo (in)competente han dado como resultado la eclosión de un proceso de turistificación, en principio urbano (Venecia, Barcelona, Madrid, Ámsterdam, Brujas, Lisboa, etc...) pero extensible a múltiples destinos de todo tipo (Benidorm, Ibiza, Dubrovnik, Santorini, Florencia, Mykonos, Malta, Islandia, Stonehenge, El Vaticano, etc.). Esta afluencia desmesurada de turistas ha provocado efectos muy negativos para los pobladores habituales de esos destinos, entre otros el desarrollo de 
la gentrificación con el consiguiente aumento del precio de la vivienda y la consecuente redistribución, obligada, de gran parte de la población residente en barrios periféricos más asequibles (Nogués-Pedregal, Travé-Molero \& Carmona-Zubiri, 2017). Sin duda, con la perturbación de la cotidianeidad y el desplazamiento obligado del anfitrión dentro de su propio entorno, debido a la presencia excesiva y la acción desordenada y constante, del turista visitante se evidencia una nueva paradoja connatural al modelo de turismo actual.

Esto conlleva para los residentes cambios sociales, culturales y económicos de carácter estructural forzados por la determinante acción de las dinámicas del modelo económico de "lo turístico". A esto habría que añadir que el riesgo de turistificación se cristaliza en dos direcciones ya que tanto el anfitrión como el huésped son receptores involuntarios de los efectos de esta situación que les satisface y perjudica. Para el anfitrión la satisfacción de los ingresos económicos derivados de las prácticas consumistas del turista significan, al mismo tiempo, los desórdenes de tipo social, a los que nos hemos referido, sin olvidar el encarecimiento del coste general de la vida. Y el turista, teniendo que compartir con multitudes los espacios no alcanza a compensar el gasto con las expectativas de placer. Como consecuencia de este proceso de turistificación han surgido movimientos sociales de ciudadanos locales en destinos que expresan su rechazo a esta suerte de invasión que origina destrucción del tejido social y provoca una reducción de la calidad de vida (Milano, 2018), y a la que se conoce como turismofobia. El desencadenamiento de esta fobia al turismo encarna una paradoja intrínseca a la propia configuración del turismo como fenómeno sociocultural y económico ya que refleja grandes contradicciones internas que se mantienen insolubles en el tiempo.

Los riesgos se extienden también al ámbito cultural donde el objetivo de rentabilidad y beneficio económico "a toda costa", sin prever y asumir los costes colaterales, desvirtúa en numerosas ocasiones la autenticidad de las prácticas culturales originarias de los anfitriones del destino. Estas comunidades locales se ven impelidas a transmutarse alterando su esencia, su espacialidad, su temporalidad, el sentimiento de profundidad comunitaria compartida, su ritualidad, en definitiva, desvirtuando sus raíces identitarias. Las prácticas culturales acaban, así, convirtiéndose en un producto comercializable, en un artificio de postureo desprovisto de los rasgos distintivos de sus atributos originarios, despojado de la sutileza de su idiosincrasia, desprendido de su "verdad". Esto representa el riesgo de un empobrecimiento del patrimonio cultural material e inmaterial de las comunidades anfitrionas, de sus tradiciones, de su folklore, de su ethos propio y único. También aquí se puede entrever la paradoja entre el fomento de una saludable interculturalidad y la conversión de la misma en una actuación estereotipada sin auténtico intercambio cultural, contradicción entre los objetivos deseables y los logros reales impulsada por las perturbaciones de una turistificación que favorece los aspectos cuantitativos en detrimento de los cualitativos.

De esta forma el riesgo de vacuidad cultural tiende a cristalizarse en una doble dirección: por un lado, forzando a las comunidades anfitrionas a una representación reduccionista de sí mismas y por otro, sustrayendo al turista su cualidad de explorador de la alteridad, conociendo e interactuando con aquellas comunidades locales que visita, ciñéndole a un estricto rol de espectador-consumidor de productos pseudo-culturales preseleccionados comercialmente, y carentes de toda espontaneidad. Por todo ello, en múltiples ocasiones la actividad turística, transformada en su praxis turistificada, refleja ser el resultado de la falta de previsión, al ignorar riesgos cada vez más cotidianos y evidentes.

En relación a este segundo tipo de riesgos socio-culturales, la COVID-19 al paralizar, prácticamente, toda actividad turística ha aportado un factor de suma importancia como es tiempo para reflexionar sobre los riesgos que corren las comunidades locales por las 
perturbaciones que hordas de turistas provocan en su forma cotidiana de vivir, y a la conservación de sus elementos patrimoniales históricos, culturales y naturales. Asimismo, el tiempo que, tan generosamente, está ofreciendo la pandemia al multiverso de "lo turístico" supone una oportunidad única para repensar un modelo que priorice la evitación de riesgos asumiendo como principio rector la seguridad en la preservación de los valores sociales y culturales en lugar de mantenerse proclive a la búsqueda de la rentabilidad como mandato teleológico.

Por último, pero no por ello menos relevante, y conectando con la sentencia anterior, ponemos el foco, según nuestro análisis, sobre un tercer tipo de riesgo generado por el turismo que tiene efectos socio-económicos negativos para las comunidades locales de los destinos turísticos, y sobre su propia estructura organizativa y económica. La industria y la actividad turística tienen su basamento en los principios de la economía capitalista. Las políticas de planificación del modelo turístico se apoyan, por lo tanto, en dichas reglas que podemos sintetizar en el mandamiento único del crecimiento constante y continuo del beneficio (Friedman, 1966). Todas las medidas que se piensan, diseñan, planean e implementan en el ámbito del turismo están presididas, tamizadas y adaptadas por y para la obtención de un sacrosanto beneficio económico cuanto mayor, mejor. La incuestionabilidad de este precepto, ubicuo y omnipotente tiene como consecuencia el surgimiento de un riesgo enorme que se traduce en minorar extraordinariamente, o incluso anular la entrada de iniciativas que fomenten la creatividad y la innovación alternativa, a través de nuevas pautas que permitan avanzar hacia modelos regenerativos de todos los universos que componen "lo turístico". Mientras tanto las prácticas económicas actuales del sector turístico llevan implícitas una serie de riesgos cuyos efectos se materializan, de manera pertinaz, sobre colectivos históricamente vulnerables, como son los trabajadores, productores del sector primario, mujeres y personas con discapacidad. Sin embargo, esta pandemia está evidenciando que una renovada intervención de estos actores de la mano de la transformación tecnológica y la digitalización de los procesos puede añadir una nueva dimensión de progreso al turismo.

Estamos refiriéndonos al necesario refortalecimiento del papel, hoy muy reducido, de las comunidades locales en el ámbito del abastecimiento de productos y servicios a los recursos turísticos que se encuentran radicados en su territorio. Siguiendo órdenes de los principios macroeconómicos de la escalabilidad y de los agentes de la distribución mayorista (empresas multinacionales y turoperadores) los productores, locales tienen pocas opciones de poner en valor tanto su trabajo personal como unas técnicas de producción respetuosas con el medioambiente y la protección de la salud de los consumidores. Esto implica otra paradoja, ya que representa un contrasentido que la mayor parte de la riqueza generada por la actividad turística en un determinado destino no redunde en beneficio de la comunidad de ese territorio, y quede en manos de las citadas corporaciones internacionales. La consideración y puesta en marcha de valores éticos que proporcionen a dichas comunidades las oportunidades que ofrece el negocio turístico en sus múltiples variaciones, sin duda, contribuirían a erradicar riesgos de gran alcance social como la pobreza, el desempleo, la desigualdad de oportunidades y la subrepresentación profesional de género, entre otras.

No obstante, resulta sorprendente que en la búsqueda permanente del crecimiento del número de visitantes y de la cuenta satélite del turismo, su industria no haya encontrado aún fórmulas, ni acometido acciones, exitosas que den solución a problemas que tras décadas de vigencia permanecen enquistados. Una de estas cuestiones pendientes, quizás la más urgente y necesaria de superar, es la excesiva dependencia de la estacionalidad y su consiguiente derivada de la discontinuidad en el empleo, en la retención del talento profesional y como 
secuela la limitación en la calidad de la oferta turística. En muchas ocasiones, la disminución, e incluso supresión, de ingresos durante ciertos períodos del año, y por la tanto de rentabilidad, procedentes de la estacionalidad redunda en un artificioso encarecimiento de la oferta de recursos, productos y servicios turísticos que ocasionan un incremento de la inflación para las comunidades locales.

Asimismo, la falta de una planificación inclusiva de la oferta, por parte de la industria, que extienda el acceso a un segmento de potenciales turistas, y cree puestos de trabajo cualificados, está incidiendo en la demora de la resolución de una cuestión tan prioritaria como es la desestacionalización. Existe una demanda real y creciente de viajes $\mathrm{y}$ experiencias turísticas encarnada en las personas con discapacidad, que está siendo, reiteradamente, desatendida. Se produce la contradicción de que la demanda supera con creces a la oferta. Esto representa un notable riesgo de índole socio-económica ya que por la característica de dicho colectivo de contar con mayor disponibilidad de tiempo libre, este podría ayudar a paliar significativamente el problema estacional en la distribución de los flujos de visitantes que arrastra el turismo de manera secular.

Las tres modalidades de riesgo examinadas tienen la capacidad de alterar significativamente la dinámica, los procesos y la propia configuración estructural de una industria como la turística, atentando contra la óptima marcha de un tejido empresarial muy diverso, sobre el empleo, sobre el consumo y, en último término, contra su propia supervivencia. Al mismo tiempo, el turismo con su actual modelo económico y organizacional constituye un poderoso y desafiante riesgo medioambiental, cultural y socioeconómico por las repercusiones adversas sobre el patrimonio histórico, social, económico, cultural y natural de las comunidades locales de los destinos turísticos. La pandemia ha evidenciado que vivimos, de manera larvada y permanente, en una sociedad del riesgo (Beck, 1988), y que con la actividad humana generamos nuevos riesgos que desvelan así su incuestionable origen social. Los riesgos tienen la capacidad de añadir incertidumbre a los inestables elementos y entornos sistémicos, como el turismo, incrementando la percepción de vulnerabilidad de los mismos.

\section{TURISMO Y VULNERABILIDAD}

Para adentrarnos en el análisis de la vinculación existente entre turismo y vulnerabilidad conviene precisar que el turismo se practica, se realiza, en un lugar, en un territorio, y por lo tanto nos interesa concretar qué entendemos por territorio vulnerable. Para ello seguiremos a Méndez cuando afirma que:
"puede definirse como vulnerables a aquellos lugares con alta probabilidad de verse afectados de forma negativa por algún acontecimiento en función de dos tipos de razones que a menudo se complementan. Por un lado, una elevada exposición a riesgos de diversa naturaleza que escapan a su control; por otro, su escasa capacidad de respuesta, tanto por sus debilidades internas como por la falta de apoyo externo para atenuar los daños provocados.” (2017: 13).

La COVID-19 ha puesto de manifiesto que el turismo como fenómeno global presenta un alto índice de vulnerabilidad al constatarse, una vez más, su exposición a riesgos de naturaleza sanitaria, y en esta ocasión de extensión planetaria, ya que no ha habido un solo lugar, territorio, destino turístico en el mundo que se haya librado de los perniciosos efectos 
de esta pandemia. Se ha mostrado, con claridad, que la industria turística, en la actualidad, no cuenta con capacidad de respuesta suficiente para minorar los daños, ni a nivel interno ni por apoyo externo.

No obstante, esta situación está en proceso de reversión gradual sobre todo por el apoyo exterior a través de la inestimable contribución de las instituciones científicas y farmacéuticas con la puesta a disposición, en tiempo record, de diferentes vacunas que están comenzando a inmunizar a la población mundial contra el virus. Asimismo, en Europa están previstas y aprobadas importantes inyecciones de liquidez a los Estados miembros para potenciar la recuperación económica general de la zona, con cuantiosas partidas para la reactivación del turismo. Estos apoyos combinados hacen presagiar una recuperación pero, sin embargo, nadie se aventura a predecir cómo será el modelo que surja y cuál será su intensidad y fluidez puesto que se trata de enfrentar una situación desconocida, nunca antes vista ni vivida. Sin lugar a dudas, supondrá un interesante test de vulnerabilidad y resiliencia. La incógnita más recurrente es aquella que cuestiona cuál será el rumbo que tomará la industria para iniciar la puesta en marcha de la maquinaria, y disminuir los indicadores de vulnerabilidad que presumiblemente volverán a ser retados en el futuro.

Existe un gran interés por conocer si se buscará volver al punto en que quedó todo antes del comienzo de la crisis, si se caerá en las fauces del gatopardismo con algunas operaciones cosméticas de escaso calado y corto recorrido, o si se abordará con determinación, aunque con la gradualidad pertinente, la labor transformativa de regeneración de la que tanto se habla. Es decir, se plantea la elección por continuar soportando los elevados índices de vulnerabilidad hasta ahora conocidos o reducirlos adoptando medidas correctoras. Es en este punto donde todos los agentes de "lo turístico" están llamados a cooperar. Es un problema de todos en el que todos deberán implicarse y del que todos serán beneficiarios.

Los efectos devastadores para el turismo que ha supuesto esta pandemia, sin parangón en toda su historia, convierten en axioma la afirmación: "la seguridad sanitaria es para el turismo su talón de Aquiles". Rebajar al máximo ese grado de vulnerabilidad extrema supone un esfuerzo de cooperación hasta ahora no realizado. Se necesitarán planes de acción directa que sean resilientes, pero también preventivos, que recojan las medidas proactivas procedentes de todas las sensibilidades involucradas. Para ello, será necesario escuchar, activamente, la voz de: turistas, industria, administraciones públicas, comunidades locales y asociaciones, especialmente del Tercer Sector, en definitiva, construir una gobernanza efectiva, eficiente y eficaz, sin eufemismos, que genere proposiciones transformativas desde la convergencia en los objetivos de desarrollo sostenible (ODS).

Los turistas constituyen el factor capital del turismo, su importancia es de un valor superlativo absoluto, ya que como afirmamos más arriba sin su participación, el sistema colapsa, el turismo pierde todo sentido. Es justamente lo que ha ocurrido como consecuencia de la pandemia, los turistas se esfumaron y el turismo, como lo conocemos desapareció. Todo está hecho para el uso del turista, la lista de servicios, productos, infraestructuras, recursos, sería interminable. Cabe preguntarse si el turista es consciente de la potencia de su figura y del poder que adquiriría si se organizara fundando un ente que representara sus intereses, sus derechos, sus iniciativas, sus expectativas, donde mostraran con claridad lo que desean y esperan encontrar durante toda la cadena de viaje en sus experiencias turísticas. No obstante, y además del citado cauce de empoderamiento, los turistas también tienen un papel crucial en el impulso de una, más que recomendable, re-estructuración de las dinámicas del sistema turístico global aportando con determinación una actitud proactiva comprometida, y criterios irrenunciables sobre la seguridad sanitaria personal y colectiva, la 
calidad medioambiental de todos los componentes del destino, el deber ético con las comunidades locales, y la distribución óptima de los flujos.

La industria está abocada a re-pensarse. Esto significa cuestionarse, autoevaluarse, autocriticarse, para obtener de ese ejercicio introspectivo ideas, mecanismos, objetivos y ánimos renovados. Ese período de reflexión debe indicarle una ruta de confluencia con el sentir y la actitud del turista postpandemia. Necesita adaptarse a un nuevo escenario, emprender un cambio de paradigma, adoptar la actitud de la seducción del turista basada en la satisfacción de sus nuevas prioridades, complacer sus expectativas de protección y seguridad, de sostenibilidad ambiental, éticas y de gestión de la fluidez espacial de su experiencia. Re-configurar el sistema de valores económicos ampliando el significado de beneficio a otras esferas adicionales y complementarias a la monetaria.

La administración pública como depositaria de las competencias normativas y rectoras del turismo, desarrolla una participación de enorme trascendencia en el tablero de "lo turístico" como es la planificación y promoción de los destinos, desde el ámbito local, más próximo, al internacional, Asume la responsabilidad de atraer turistas para dar a conocer su patrimonio al exterior, favorecer la empleabilidad de la población, y la prosperidad del tejido empresarial. No obstante, en el nuevo escenario, y para contribuir a la transformación que el turismo necesita, ante la renovada demanda de los nuevos turistas, las administraciones necesitan apostar por el control en la gestión de los flujos adaptándolos a un equilibrio distributivo de la oferta y la demanda que evite los perjuicios de la turistificación. A tal fin puede, y debe, contribuir a la implementación de los avances tecnológicos y digitales disponibles más los que, a buen seguro, seguirán incorporándose. Como expresión de una gobernanza eficiente a través de relaciones recíprocas y multilaterales entre lo público y lo privado se pueden fomentar convenios de complementariedad en la oferta de destinos que se encuentren dentro de un cierto radio de proximidad. Estos acuerdos ampliarían la oferta ofreciendo nuevas oportunidades, atractivas y sostenibles que, además, favorezcan la preservación de su patrimonio, la creatividad y la innovación contribuyendo notablemente al reparto de la carga y abriendo vías a la desestacionalización.

Las comunidades locales están llamadas a incorporarse activamente al nuevo escenario. Dicha participación ha de estar presidida por el compromiso y la acción cooperativa de los agentes antecitados dando lugar a una fecunda relación de beneficio multilateral. Las comunidades anfitrionas tienen un papel fundamental en el resultado final de la experiencia turística. Unas veces con intervención directa en la producción de bienes y mercancías, otras en su distribución, a menudo en la creación y exhibición del patrimonio cultural. La existencia de un sólido tejido asociativo es fundamental para una interlocución eficiente con el conjunto de agentes e instituciones que aborden la elaboración de planes y la implementación de medidas a corto, medio y largo plazo. Entre alguna de estas decisiones estarían las de acordar precios competitivos, regulación del alquiler vacacional y establecer los aforos apropiados que eviten la saturación del entorno.

Continuando con la relación entre turismo y vulnerabilidad nos referimos, como recién anunciábamos, a las asociaciones del Tercer Sector que engloban a colectivos que se caracterizan por ser vulnerables lo que no les impide mostrar un interés creciente por hacer turismo con la misma dignidad que el resto. Sin embargo, estas personas encuentran múltiples y distintas limitaciones de acceso a los productos, servicios y recursos turísticos que obstaculizan el disfrute "normal" de una experiencia turística estándar. Un modelo transformador, sostenible y regenerador del turismo pasa, sin ambages, por ser inclusivo y 
como "promete", solemnemente, la Agenda 2030 para el desarrollo sostenible en su preámbulo, "sin dejar a nadie atrás".

De este mandato inequívoco se infiere la necesaria inclusión de estos colectivos que, a través de sus representantes, han de estar presentes, y tenidos en cuenta, siendo escuchados en sus alegaciones e iniciativas, como un agente más, dispuestos a contribuir con sus aportaciones a enriquecer el nuevo paradigma reivindicando la plena inclusión. La incorporación al turismo de estos colectivos, además de constituir un gran avance ético, supone un impulso de gran magnitud al desarrollo socio-económico del turismo por el crecimiento exponencial de turistas que se incorporan al ciclo de negocio (Cruces, 2015), con el potencial añadido de colaborar a la desestacionalización del sector y la actividad. Aquí, la vertiginosa transformación tecnológica a la que estamos asistiendo, también podrá aportar su valiosa cuota de integración social, de democratización de la cultura y, como facilitadora de la gestión de la accesibilidad universal. Todas estas contribuciones representan una muestra muy significativa del papel positivo que la tecnología, desde la perspectiva de su operatividad objetiva, puede generar al turismo y sus riesgos asociados, mostrándola, a su vez, como reverso de aquella concepción negativa que, como "subpolítica", atribuye Beck (1988) en su "sociedad del riesgo" a la tecnología como dominio.

\section{EL TURISMO POSTPANDEMIA: RETO Y OPORTUNIDAD DE TRANSFORMACIÓN}

La pregunta más recurrente, que concita más interés, y que entraña mayor incertidumbre es la que cuestiona si el turismo asumirá, cuando se restablezca la movilidad internacional, los cambios sustanciales que desde numerosos foros e instituciones se le solicitan, o buscará como única prioridad recuperar, cuanto antes, los resultados prepandemia en términos de número de visitantes internacionales y su contribución al PIB mundial, postergando dichos cambios.

El escenario es tan inédito que nadie se aventura a vaticinar una respuesta que pronostique el rumbo que seguirá el turismo postpandemia. De forma patente confluyen los componentes de, lo que se ha dado en llamar, entorno VUCA, acrónimo que refiere a la volatilidad, incertidumbre, complejidad y ambigüedad de las condiciones y situaciones de un fenómeno. El turismo, como la creación más perfecta y sofisticada del sistema de valores capitalista, en palabras de Nogués Pedregal (Yanes y Travé, 2020) nunca antes había tenido que pasar un escrutinio tan severo y frontal sobre la consistencia de la estructura de su modelo. Los cuestionamientos sobre el modelo tienen diferente procedencia, algunos de ellos son una auténtica enmienda a la totalidad, otros sugieren cambios parciales y progresivos de mayor o menor intensidad. Entre estos últimos hay un sector de la propia industria, cada vez más activo, a favor de dar un paso, incluso, más allá de la tan traída y llevada sostenibilidad para dirigirse hacia la meta más ambiciosa de la regeneración. Porque, como preconizan sus defensores, no se trata sólo de mantener una situación dada sino de recuperar lo perdido por mor de un crecimiento ilimitado, erróneamente encumbrado como valor supremo, y de efecto extenuante para las comunidades locales y el medioambiente. Representa una gran incógnita el margen de maniobra con que cuenta el sistema para su presunta, y deseable, regeneración aunque, sin duda, este desconocimiento no reduce un ápice la conveniencia de embarcarse en un proyecto con semejante objetivo. 
Sin embargo, y a pesar de que aumenta el eco de las voces disonantes con el único modelo conocido de turismo basado en la masificación sin límites en pos del crecimiento económico infinito, estos valores superiores están tan arraigados en el devenir de las dinámicas cotidianas de las sociedades modernas globalizadas y, si cabe, aún más en las dinámicas del turismo, que transmiten una suerte de mandato dogmático de incuestionabilidad sobre sí mismos. Esta circunstancia permite vislumbrar el posicionamiento aventajado de la tesis de la continuidad del modelo. Por lo tanto, cabe preguntarse si existe un prerrequisito básico que pueda favorecer la sustitución de esos valores, ¿cuál es ese prerrequisito?, y ¿a quién corresponde activar la iniciativa transformadora?, Incluso, habría una reflexión aneja a estas cuestiones como es la aceptación del desafío implícito, y el consiguiente compromiso de acción que conlleva.

Para responder a la pregunta de cuál es ese prerrequisito nos tenemos que referir, como también vaticina Nogués, al necesario cambio social que ha de preceder a la sugerida transformación del modelo turístico. Pero, la factibilidad de ese cambio social extenso tiene, a su vez, que venir precedido de una transmutación del valor de todos los valores: el individualismo. Se antoja complicado pensar en la llegada de un nuevo modelo de turismo que con un enfoque sostenible busque la regeneración del ecosistema donde la actividad turística se ha de producir, si no hay un giro copernicano que sustituya la rotación en torno al eje de la hegemonía de los intereses individuales, hasta configurar una nueva órbita que circunde el interés general del bienestar de la comunidad. Se trata de una traslación axiológica en la conciencia de "lo turístico", como todo sistémico, que transforme la mentalidad de cómo percibimos el hecho de hacer turismo. Para ello, es preciso el surgimiento de un movimiento de abajo-arriba impulsado por un grupo que comparta creencias y trabaje unido para crear una versión de turismo que genere un beneficio neto real produciendo mayores efectos positivos que negativos (Pollock, 2012).

Estas propuestas disruptivas pretenden comenzar a cambiar la mentalidad con la puesta en escena de nuevos valores que piensen la abundancia en términos de suficiencia y no como exceso. Desde esta nueva hermenéutica se considera la maximización del beneficio en términos más amplios y diversos del concepto de enriquecimiento económico desviando el foco de lo meramente pecuniario a la riqueza expresada como bienestar donde se prioriza la calidad a la cantidad. Otro factor de crucial importancia está en centrar la atención en que la experiencia del viaje radica en el encuentro con el otro concibiendo como unidad principal de la actividad turística la relación co-creadora de valor entre personas, en lugar de una transacción que está formulada para obtener una ganancia en el intercambio de bienes o servicios.

Una propiedad adicional es la que representa al destino como algo único, con su luz única, su clima único, su ecología, su historia y su cultura que lo hacen diferente a todos los demás, otorgándole la oportunidad de ofrecer una experiencia única. Aun siendo innegable que los turistas necesitan ser alojados, transportados, alimentados y entretenidos, desde esta perspectiva estos servicios han de ser provistos de manera que respeten y reflejen el valor añadido de un entorno singular y exclusivo que sirva como revulsivo contra los procesos de paquetización, la uniformidad y mediocridad actuales. Esta nueva mirada a los destinos busca resaltar los detalles prestando mayor atención a lo pequeño, lo hecho a mano, lo calmado para lograr una mayor integración del turista. Se busca involucrarle dotando, así, la experiencia de significado, de propósito y despertando la curiosidad que desemboque en relaciones más completas y mejor valoradas. Esto conlleva más apreciación del destino en su conjunto, lo que conduce, a su vez, al incremento del valor y éste a un mayor rendimiento (Pollock, 2012). 
La pandemia ha venido a traslucir la coincidencia entre estas iniciativas y la tendencia mostrada por los que han podido viajar durante este tiempo de restricciones. Ha quedado patente que viajar y explorar como turistas las comunidades más cercanas puede ser una práctica muy atractiva, más económica y más sostenible medioambiental, social y culturalmente. Esta realidad, ha sido forzada por las circunstancias sanitarias, pero no por ello deja de suponer un ejemplo, una guía para abordar procesos innovadores de redistribución de los flujos de turistas al que la seducción mercadotécnica podría contribuir a mejorar.

Estas recomendaciones ponen el foco en aspectos con una profunda carga socioantropológica como el cambio social y la vida de las comunidades, así como en la protección y la revitalización que las culturas necesitan, no obstante, deberían imbricarse con una nueva concepción de la economía que intervenga de manera transversal en los recursos, las prácticas, las dinámicas y los procesos que configuran el modelo turístico. Nos estamos refiriendo a la economía circular.

La economía circular es un modelo económico alternativo al actual. El patrón predominante en nuestros días se caracteriza por ser lineal, en el que los recursos se extraen, se produce, se consume y se desecha. Sin embargo, la variante circular se plantea desde una concepción sistémica que contempla la economía, la ecología y la sociedad como elementos que interactúan con mutua dependencia. Los principios que guían este modelo económico se sintetizan en tres medidas básicas conocidas como las 3R: Reducir, Reutilizar y Reciclar, que otros autores como Heriz (2018) han aumentado hasta 5R, con la incorporación de Rediseñar el funcionamiento de todo el sector convirtiendo los productos en servicios, $\mathrm{y}$ Reparar productos que añadan valor al extender la vida útil de los mismos.

Este planteamiento está estrechamente vinculado al enfoque general de la sostenibilidad extendiéndose con especial énfasis al sector turístico y sustentándose en tres ejes: medioambiental, económico y socio-cultural. Este modelo necesita de un liderazgo institucional que asuma la responsabilidad de impulsar los cambios que inicien y establezcan nuevas formas de producción y consumo sostenible en los destinos. Simultáneamente, ha de darse la participación de las sociedades locales y los visitantes en el desarrollo de los nuevos procesos sostenibles como expresión del capital social consustancial al turismo. A todo esto hay que añadir el apoyo de los valores éticos que contribuyan a la protección de la naturaleza, el respeto a la identidad cultural y la organización social del territorio. Asimismo, se precisa de la intervención de una adecuada gestión del conocimiento con la implementación de un sistema de inteligencia que recopile datos de los cambios en el entorno para desarrollar estrategias que corrijan los impactos negativos y mejoren la competitividad. En definitiva, la economía circular basada en las medidas apuntadas se dirige hacia un objetivo que se podría denominar "turismo circular" entendiendo por tal "el modelo turístico que permite no sólo la protección del patrimonio cultural y natural a través de la disminución de la extracción de recursos y de la reducción de las externalidades negativas, sino también la regeneración del capital natural del territorio, lo que permite contar con destinos turísticos líderes en calidad e innovación.” (Gaztelumendi, et al, 2019: 99).

Para cerrar el círculo subrayaremos la relevancia de una adecuada optimización de la gestión inteligente de los destinos refiriéndonos al modelo pionero de Destinos Turísticos Inteligentes (DTI) promovido por la Sociedad Mercantil Estatal para la Gestión de la Innovación y las Tecnologías Turísticas (SEGGITUR). Esta iniciativa se encuentra en continuo crecimiento en España, contando en la actualidad con 251 miembros de los que 154 son destinos, 40 instituciones y 57 empresas. Asimismo, está previsto exportar el modelo a Latinoamérica y Caribe habiéndose producido en el mes de diciembre de 2020 las 
dos primeras incorporaciones a la Red DTI por parte de los destinos de Tequila (México) y Medellín (Colombia).

Un destino turístico inteligente (DTI) se define como "un espacio turístico innovador, accesible para todos, consolidado sobre una infraestructura tecnológica de vanguardia que garantiza el desarrollo sostenible del territorio, facilita la interacción e integración del visitante con el entorno e incrementa la calidad de su experiencia en el destino y la calidad de vida de los residentes" (Gaztelumendi, et al, 2019: 14)

El modelo se apoya sobre 5 pilares fundamentales que son la innovación, la tecnología, la accesibilidad, la sostenibilidad y la gobernanza. Se fomenta la creatividad en proyectos innovadores que propongan iniciativas vanguardistas que desarrollen una economía circular respetuosa y vinculada a los demás pilares. La tecnología como herramienta facilitadora de datos para facilitar la toma de decisiones que evite los impactos negativos sobre los recursos y las personas. Un DTI tiene que ser inclusivo para lo que ha de tener muy presente la accesibilidad universal para todas las personas que vivan y visiten el destino. Asimismo, los tres ejes de la sostenibilidad que exigen un respeto minucioso al medioambiente, a las comunidades locales favoreciendo su participación en todos los órdenes relacionados con el turismo, sin olvidar la progresiva introducción de nuevas pautas económicas de carácter circular que logren ser competitivas. Y todo ello presidido por una vigorosa gobernanza compartida por todos los grupos de interés: las diversas administraciones, el conjunto del tejido empresarial, asociaciones comunitarias, etc.

Las propuestas que hemos expuesto ya estaban encima de la mesa con anterioridad a la irrupción de la pandemia, ésta con su vehemencia lo que ha traído, además de los destrozos, es el enorme reto en forma de oportunidad de centrar el foco sobre los problemas endémicos de una actividad que debe resurgir con aires renovados.

\section{CONCLUSIONES}

Después de realizar un recorrido por las paradojas inherentes al modelo de turismo imperante hemos constatado que dichas contradicciones son el resultado de la falta de previsión de una serie de riesgos de diferente índole que evidencian los defectos estructurales de un sistema de relaciones interdependientes marcadas de manera determinante por objetivos económicos dirigidos al crecimiento ilimitado del beneficio. En una "sociedad del riesgo" como la actual, la pandemia del COVID-19 ha disparado los índices de vulnerabilidad a los que, habitualmente, está expuesto el turismo reduciendo ostensiblemente su actividad mediante una significativa limitación de la movilidad de turistas en todo el mundo. Esta circunstancia inédita ha llevado al multiverso de "lo turístico" a un período de reflexión sobre la conveniencia de repensar, reconfigurar y por último transformar el modelo actual de hacer turismo priorizando aspectos, hasta ahora relegados. Desde múltiples foros e instituciones especializadas se aboga por la elección del enfoque sostenible con una sólida apuesta por el cuidado del medioambiente y la biodiversidad de sus ecosistemas, por dar una mayor participación en la economía a las comunidades locales respetando su idiosincrasia y su identidad cultural.

A través de la apuesta por la sostenibilidad se pretende alcanzar una regeneración del sistema complejo de "lo turístico". Concluimos que para ello se precisa una transmutación de valores, como el individualismo, lo que significa un verdadero seísmo axiológico, y prerrequisito del cambio social de abajo-arriba que necesitan las estructuras del turismo. Solo a partir de un giro copernicano de tal calado se pueden afrontar paradojas de 
consecuencias tan nocivas como las que están produciendo la turistificación y la carencia de creatividad en ideas y medidas que sirvan para resolver el problema endémico de la estacionalidad.

Otra consecuencia de la pandemia es la aceleración del proceso de transformación tecnológica al que estamos asistiendo y que abre una amplia ventana de posibilidades para la metamorfosis del modelo de turismo. Las innovadoras aportaciones de la Inteligencia Artificial, la Realidad Virtual, el Blockchain, la Realidad Aumentada, la Robótica, etc., y su extraordinaria capacidad para captar cantidades gigantescas de datos, clasificarlos, interrelacionarlos, sintetizarlos y analizarlos, facilitan significativamente su comprensión para la prevención de riesgos, la reducción de los impactos, y cualificar la toma de decisiones. La Red DTI está realizando un trabajo pionero y muy eficiente al integrar tecnología, innovación, accesibilidad, sostenibilidad y gobernanza en un conjunto con gran potencialidad transformadora. Adicionalmente, los postulados de la economía circular constituyen un coadyuvante con gran poder impulsor de cambio.

Esta pandemia supone un apercibimiento para las sociedades de la modernidad ulterior que exprimen sinfín todo tipo de recursos. Un inapelable toque de atención para el turismo.

No obstante, como hemos mostrado existen propuestas que están llamadas a alcanzar un elevado protagonismo en la tarea de convertir el reto de sacar al turismo de esta crisis multidimensional en una oportunidad transformadora del modelo desde un enfoque sostenible e impulsado por dinámicas regeneradoras.

\section{BIBLIOGRAFÍA}

Beck. U. (2002). La Sociedad del Riesgo. Ediciones Paidós Ibérica: Barcelona.

Beck, U. (2004). Vivir en la sociedad del riesgo mundial. CIDOB Edicions: Barcelona.

Britto, F., S. Alencar. (2013). Riesgos ¿qué riesgos? Estrategias de reducción de riesgos y participación emocional de consumidores de turismo aventura. Estudios y Perspectivas en Turismo, Vol. 22, (1), pp. $65-83$.

Cruces, R. (2015) "Removing 'invisible' barriers: opening paths towards the future of accessible tourism" Journal of Tourism Futures, Vol. 1, Iss 3, pp. 269 - 284.

De la Calle, M. (2019). Turistificación de centros urbanos: clarificando el debate. Boletín de la Asociación de Geógrafos Españoles, 83, 2829, pp. 1-40.

De la Torre, M., D. Navarrete. (2013). Turismo, Violencia y Vulnerabilidad. Kairos, 17 (31), pp. 114.

Fernández, S. (2021). Historia interminable de la crisis del Coronavirus en España: entre olas y vacunas. La Razón Histórica, 51, pp. 1-15.

Friedman, M. (1966). Capitalismo y libertad. Ediciones Rialp. Madrid.

Fuchs, G. \& Reichel, A. (2010). "Health Tourists Visiting a Highly Volatile Destination". Anatolia, an international Journal of Tourism and Hospitality Research. Vol. 21 (2): pp. 205-226.

Gaztelumendi, I., Tarí, A., \& Mora, D. (2019). Informe sobre Economía Circular aplicada al Turismo. SEGITTUR Turismo e Innovación. Disponible en: https://www.segittur.es/wpcontent/uploads/2019/09/Informe-sobre-econom\%-C3\%ADa-circular-aplicada-al-turismo-ok.pdf (Consultado: 25 de abril de 2020).

Heriz, I. (2018). Economía circular: un nuevo modelo de producción y consumo sostenible. Tébar Flores. Madrid.

Jafari, J. (1988). Función y Estructura del Turismo. Algunos aspectos antropológicos sobre el turista y su mundo. Anthropológica, Revista de Etnopsicología y Etnopsiquiatría, 4, $29-50$.

Jordano, P. (2017). ¿Qué es la dispersión a larga distancia? Y una taxonomía de eventos de dispersión. Revista de Ecología; 105: 75-84. 
Joo, H., Maskery, B. A., Berro, A. D., Rotz, L. D., Lee, Y., \& Brown, C. M. (2019). Economic impact of the 2015 MERS outbreak on the Republic of Korea's tourism-related industries. Health Secur; $17(2)$, pp. 100-108.

Korstanje, M. E. (2013). Nuevo modelo para comprender al riesgo turístico. Turydes, V. 6 (14). pp. 112.

Korstanje, M. E. (2020) El COVID-19 y el turismo rural: una perspectiva antropológica. Dimensiones Turísticas [Número especial: Turismo y COVID-19], 4, pp. 179-196.

Lorenz, Edward N. (2000), La esencia del caos, Editorial: Debate. Madrid.

Mauss, M. (1979). Sociología y Antropología. Tecnos. Madrid.

Menchero, M. (2020). Flujos turísticos, geopolítica y COVID-19: cuando los turistas internacionales son vectores de transmisión. Geopolítica(s), 11(Especial) 2020: pp. 105-114

Méndez, R. (2017). De la hipoteca al desahucio: ejecuciones hipotecarias y vulnerabilidad territorial en España. Revista de Geografía Norte Grande, (67), 9-31.

Milano, C. (2018). Overtourism, malestar social y turismofobia, Un debate controvertido. Pasos, Vol. 16 (3). pp. 551-564.

Naciones Unidas. (2015). Resolución de la Asamblea General que aprueba el texto, "Transformar nuestro mundo: Agenda 2030 para el desarrollo sostenible”. (Consultado en:) https://unctad.org/system/files/official-document/ares70d1 es.pdf. (Accedido: 22-4-2021)

Nogués-Pedregal, A.M., Travé-Molero, R., Carmona-Zubiri, D. (2017). Thinking against "empty Shells" in tourism development projects. Etnoloska Tribina, 47(40), 88-108.

Pollock, A. (2012). "Conscious Travel: Signposts Towards a New Model for Tourism". 2nd UNWTO Ethics and Tourism Congress, September 12th, Quito.

Posada, E. (2020). Ecologística: Estrategia basada en las 5Rs para la satisfacción de necesidades. Ciencia Matria, 6 (11), pp. 165-182.

Rodriguez-Toubes. D., Álvarez de la Torre, J. (2013). Vulnerabilidad del Turismo y Comunicación Institucional ante desastres: Estudio de casos. REDMARKA, VI (11), pp. 137-161.

Valle, A. S. (2020). La industria turística y el impacto del COVID-19. Escenarios y propuestas. Global Journey Consulting: Madrid.

Yanes, S., Travé, R. (2020). El turismo o la creación más perfecta y sofisticada del sistema de valores capitalista: Una entrevista a Antonio Miguel Nogués Pedregal. Perifèria, revista de recerca $i$ formació en antropologia, 25(3), 174-207. https://doi.org/10.5565/rev/periferia.819

\section{Breve currículo}

\section{Rafael Cruces Portales}

Rafael Cruces es doctor en Antropología Social y Cultural por la Universidad Miguel Hernández de Elche (UMH) y pertenece al grupo de investigación CULTURDES de dicha universidad. Sus temas de interés en investigación son preferentemente el turismo accesible y la sostenibilidad turística desde una perspectiva socio-antropológica. 